\title{
PERSPECTIVA GENERAL DE LA NORMATIVA SOBRE EL AGUA EN LA CORONA DE CASTILLA Y EL TERRITORIO MADRILEÑO DURANTE EL ANTIGUO RÉGIMEN
}

\author{
María Jesús ToRQuemada SÁnCHez \\ Profesora Titular de Historia del Derecho \\ y las Instituciones de la UCM \\ mariajesustorquemada@der.ucm.es
}

\begin{abstract}
RESUMEN
Los recursos hidricos existentes en un territorio ban marcado de forma notable el modo de vida de sus habitantes desde épocas remotas. En este caso se ofrece una panorámica de la manera en que la secular escasez del agua en el interior peninsular, y, más concretamente, en el espacio que boy conforma la Comunidad Autónoma de Madrid, ha influido en la regulación de su aprovechamiento. Los órganos políticos, llamados a la resolución de los conflictos ocasionados por las carencias de tan vital recurso, se han esforzado a lo largo de los siglos para generar un sistema normativo que pudiera salir al paso de tales controversias, pero los intentos de acaparar el agua han dificultado la convivencia entre las poblaciones madrileñas desde antiguo y nunca se arbitró un orden jurídico verdaderamente eficaz para atajar tales inconvenientes. Demasiados intereses se hallaban en juego. Ello es esencialmente debido a la peculiaridad que, a tal efecto, ha supuesto bistóricamente la capitalidad de Madrid, al ser necesario conjugar dentro de la región los intereses cortesanos con los de ciertos señorios y los puramente municipales. La superposición de diferentes estamentos políticos entrañaría a lo largo de la bistoria madrileña una evidente dificultad a la hora de repartir el caudal bídrico del territorio.
\end{abstract}

Palabras clave: Agua, normativa, Madrid, conflicto, Corte, señorío, municipio.

ABSTRACT

A land's bydraulic resources have remarkably marked its inbabitants' lifestyle from ancient times. Here we offer an overview of the way in which the secular scarcity of inland water and, in particular, the space which today shapes the Autonomous Community of Madrid, has influenced the regulation of its use. Political bodies, aimed at conflict solution caused by the flaws of such a vital resource, have been trying for centuries to generate a regulation system that could get beyond such controversy but the attempts to capture water have made it difficult for the different settlements in Madrid to cohabitate since old times and a truly efficient legal order to contain such disadvantages has never been arbitrated; there were too many interests at stake. This peculiarity derives from the idiosyncrasies of Madrid's historical status as capital city, being necessary within the region to combine courtesan inter- 
María Jesús Torquemada Sánchez Perspectiva general de la normativa sobre el agua...

ests with those from certain seigneuries and the mere local interests. Superposition of different political estates would imply throughout the history of Madrid a clear setback when it comes to sharing the bydraulic water level of the territory.

Keywords: Water, Regulation, Madrid, Conflict, Court, Seigneury, Municipality.

\section{ZUSAMMENFASSUNG}

Die bestehenden Wasserressourcen innerhalb eines Territoriums haben seit Urzeiten wesentlich die Lebensweise der Bewohner bestimmt. Im vorliegenden Fall wird eine Übersicht geboten, die darstellt, wie die seit Jabrhunderten bestebende Wasserknappheit im Landesinneren der Halbinsel, und speziell im Raum den beute die Autonome Region Madrid einnimmt, Einfluss auf die Regulierung des Wasserverbrauchs genommen hat. Die politischen Organe, die zur Lösung der durch die Wasserknappheit entstandenen Konflikte angerufen wurden, baben sich bemübt, im Laufe der Jabrbunderte ein Regelwerk zu schaffen, dass diese Streitigkeiten bebeben kann., jedoch haben die Versuche der Wasserbevorratung das Zusammenleben zwischen den Ortsgemeinden Madrids von altersher erschwert und nie wurde eine wirklich effiziente juristische Schiedsordnung verabschiedet, die diese Schwierigkeiten hätte beheben können. Es waren zu viele Interessen im Spiel. Das ergibt sich insbesondere aus der Besonderheit, dass Madrid Hauptstadt war und die Interessen des Hofstaats, des diversen Territorialadels und der Ortsbevölkerung in Einklang zu bringen hatte. Die Überordnung verschiedener politischer Instanzen stellte im Laufe der madrilenischen Geschichte erwiesenerma en eine Erschwernis bezüglich der Wasserverteilung dar.

Schlüsselwörter: Wasser, gesetzliche Regelung, Madrid, Konflikt, Hofstaat, Territorialadel, Ortsgemeinde.

SUMARIO: I. GENERALIDADES SOBRE LA ADMINISTRACIÓN DE LAS CORRIENTES DE AGUA EN LA HISTORIA MADRILEÑA.-II. NORMATIVA TERRITORIAL.-III. LAS NORMAS DE CARÁCTER LOCAL Y SEÑORIAL.-IV. PANORÁMICA SOBRE LAS CIRCUNSTANCIAS ESPECÍFICAS DE LA REGIÓN MADRILEÑA COMO SEDE Y ENTORNO DE LA CORTE.-V. ORGANIZACIÓN POLÍTICO-ADMINISTRATIVA PARA LA GESTIÓN DE LOS RECURSOS HÍDRICOS DURANTE EL ANTIGUO RÉGIMEN.-VI. OBSERVACIONES FINALES.

\section{GENERALIDADES SOBRE LA ADMINISTRACIÓN Y REGULACIÓN DE LAS CORRIENTES DE AGUA EN LA HISTORIA MADRILEÑA}

Como bien esencial que es, el agua ha venido siendo objeto de regulación durante todas las épocas y en todos los lugares donde se han producido asentamientos humanos.

Claro está que existen periodos remotos en los cuales resulta muy difícil llegar a conocer la forma en que las autoridades regulaban el uso y apro- 
vechamiento de tan preciado elemento. Sin embargo, conviene de entrada poner de manifiesto que la posesión y utilización del mismo nunca ha sido cuestión pacífica y menos en suelo hispánico, a causa de la escasez de dicho recurso por razón de las especiales características climáticas, geográficas, edafológicas, etc., que configuran el territorio peninsular.

En el caso concreto de la región madrileña, los primitivos pobladores se abastecían exclusivamente de los rebosaderos y manantiales que discurrían libremente por la superficie del territorio. Las poblaciones fueron surgiendo alrededor de esas corrientes de agua.

Se habla, además, de grandes deforestaciones que tuvieron lugar por la acción directa del hombre sobre el suelo rústico durante prolongados periodos bélicos, cuando se consideraba necesario asolar grandes territorios con el fin de convertirlos en zonas yermas que no pudieran ser aprovechadas ulteriormente por el enemigo, práctica que habría tenido lugar durante demasiados siglos de luchas entre las tropas cristianas y las musulmanas.

También contribuirían a dicha deforestación los aprovechamientos abusivos de la flora que rodeaba las grandes poblaciones durante la Edad Moderna, a causa del desmesurado crecimiento de algunas urbes peninsulares, especialmente Madrid, que, como capital de un imperio, atraía multitud de pobladores deseosos de beneficiarse de las ventajas sociales y económicas que suponía el hecho de residir en la Villa y Corte. Las exorbitadas necesidades de madera para la construcción de edificios y como combustible calefactor en invierno harían insuficientes algunos intentos llevados a cabo por los reyes castellanos tendentes a conseguir la repoblación de los bosques y los montes.

A todo ello conviene añadir la circunstancia de que, sobre todo durante el siglo XVIII, los astilleros españoles se convertirían en ingentes factorías ávidas de recursos madereros que se utilizarían para renovar la flota mercante tras la pérdida del monopolio comercial que antes tenía la sevillana Casa de Contratación ${ }^{1}$.

La suma de todas las circunstancias anteriormente expresadas implicó la continua desertización de las zonas antes boscosas y fértiles²

${ }^{1}$ La supresión del monopolio que tenía la Casa de Contratación sevillana sobre el comercio con las Indias trajo consigo la posibilidad de renovar la marina mercante a través de barcos mayores que los existentes con anterioridad. Éstos eran de pequeño calado con el fin de facilitar su navegación río arriba por el Guadalquivir hasta Sevilla, o río abajo desde dicha ciudad hasta la desembocadura.

2 Emilio Cruz Aguilar, La destrucción de los montes (aspectos histórico-jurídicos), Madrid, Publicaciones de la UCM, 1994. 
Los territorios privados de vegetación, especialmente de las especies leñosas, fueron creciendo de manera exponencial. Se trataba de un típico círculo vicioso que responde a ciertas reglas de la naturaleza y en virtud del cual, a menos vegetación, menos lluvias, y viceversa.

Cabe destacar en este punto que, a causa de la falta de previsión de las autoridades, nunca se adoptaron medidas tajantes tendentes a solucionar la carencia de recursos hídricos.

Este problema afectó principalmente a las regiones del centro y del sur peninsular que no se beneficiaban de grandes corrientes fluviales, como es el caso del territorio madrileño.

Así pues, hay que empezar por advertir el carácter insuficiente de la legislación relativa al agua durante el siglo XVIII. Aparte de la parquedad y escasez de los preceptos generales o territoriales, conviene destacar la dispersión normativa propia de la época y la naturaleza en no pocas ocasiones arcaica de los preceptos destinados a regular los acuíferos.

Si nos referimos de manera concreta a la región madrileña, se debe recordar que algunos afluentes del río Tajo han venido regando y abasteciendo de agua las comarcas madrileñas y sus habitantes desde épocas muy remotas. Son algunos de esos afluentes directos el Jarama, el Guadarrama y el Alberche, no siendo ninguno de ellos totalmente madrileño. El más caudaloso y largo es el Jarama, que recibe por la izquierda al Henares y Tajuña, y por la derecha al Manzanares ${ }^{3}$.

Hechas estas advertencias, podemos llevar a cabo una clasificación genérica de los cuerpos normativos en los cuales se contienen las disposiciones que atañen al tema y periodo que nos ocupan. Conviene adelantar que tales fuentes, no siempre de carácter legal, tenían orígenes diversos, de forma que no era infrecuente hallar contradicciones entre ellas a la hora de regular una determinada institución. La armonización de todos los instrumentos jurídicos, especialmente los de origen municipal, se presentaba como el principal escollo a la hora de resolver los conflictos entre las distintas personas físicas y jurídicas interesadas en los aprovechamientos de las corrientes de agua. p. 17.

3 Campaña Educativa sobre el Agua en Madrid, MOPU y Comunidad de Madrid, 1986, 


\section{NORMATIVA TERRITORIAL}

El Derecho territorial castellano había incluido algunas disposiciones referentes al uso y aprovechamiento del agua dentro de los textos generales elaborados durante la Baja Edad Media, siendo éstas de obligado cumplimiento en toda la Corona de Castilla. Esas leyes respondían básicamente a la filosofía heredada del viejo Derecho romano, insertado en la legislación castellana a través del Derecho común generado durante la Baja Edad Media, de manera que en ellas se consideraba el agua como un bien al que todos debían tener acceso, sobreentendiéndose siempre el superior patrocinio del rey sobre el mismo. Las Partidas, referencia obligada para este tema por su carácter omnicomprensivo, aluden al carácter público de las aguas pluviales y marítimas ${ }^{4}$.

En cuanto a los ríos, el código alfonsino también los considera dentro de la categoría de dominio público, pero distingue en este caso que deben quedar a salvo los derechos de los propietarios ribereños, estableciendo una serie de actuaciones que éstos deben tolerar a pesar del señorío que ejercen sobre las orillas ${ }^{5}$. Se trata de un precedente de la cesión de las prerrogativas del dominio en aras de la utilidad pública o el interés social.

${ }^{4}$ Los códigos españoles concordados y anotados, t. III, Código de Las Siete Partidas, t. II, que contiene la Tercera, Cuarta y Quinta Partida, Madrid, 1848. Partida 3, 28, 3: «Las cosas que comunalmente pertenecen a todas las criaturas que viven en este mundo son éstas: el aire y las aguas de la lluvia y el mar y su ribera, pues cualquier criatura que viva puede usar de cada una de estas cosas según le fuere menester, y por ello todo hombre se puede aprovechar del mar y de su ribera, pescando y navegando y haciendo allí todas las cosas que entendiere que a su provecho serán». En esa misma línea está El Espéculo, ibid., V, VI, 1849, libro V, tít. VIII, ley II: «A todos los omes dezimos que son comunales los ríos e los puertos, ca todos deven beber de las aguas, e banarse en ellas, e lavar sus cosas e secarlas en las riberas, e traer barcos por los ríos, e arrivar a las orielas e atarlos con sus cuerdas, e pescar con anzuelo e con redes pequeñas asi como esparver, o buytrón, o otras tamañas, o menores que se puedan ayudar los pobres, e ganar con que vivan de manera que los señores de los ríos non reciban grant menoscabo en las rendas de los pescados [...] e por eso son dichas comunales, porque non puede ninguno dezir apartadamientre que son suyas mas que dotro».

5 Ibid., 3, 28, 6: «Los ríos y los puertos y los caminos públicos pertenecen a todos los hombres comunalmente, en tal manera que tanto pueden usar de ellos los que son de otra tierra extraña, como los que moran y viven en aquella tierra de donde son; y comoquiera que las riberas de los ríos sean, en cuanto al señorío, de aquellos cuyas son las heredades a las que están ayuntadas, con todo eso todo hombre puede usar de ellas ligando a los arboles que allí están sus navíos y adobando sus velas en ellos y poniendo allí sus mercadurías, y pueden los pescadores poner allí sus pescados y venderlos, y en jugar allí sus redes, y usar en las riberas de todas las otras cosas semejantes de estas que pertenecen al arte o al menester por los que viven». 
El fomento de la navegación fluvial y del uso público de los ríos resulta patente en otra ley de Partidas que prohíbe taxativamente llevar a cabo ciertas edificaciones y actuaciones en las riberas de las corrientes fluviales, cuando éstas entorpezcan o impidan la libre utilización de las mismas o la navegabilidad de sus aguas ${ }^{6}$.

Atribuyen las Partidas a las poblaciones con carácter particular y en calidad de bienes comunales, las fuentes y los arenales de las riberas que se hallan dentro de su término municipal, con la precisión de que en este caso sólo pueden acceder al libre disfrute de tales bienes quienes ostenten la condición de vecinos de tales poblaciones. Los extraños sólo podrían servirse de ellos con el permiso de los moradores ${ }^{7}$.

También hallamos en las Partidas las líneas maestras de la consideración jurídica que tendrían las alteraciones en el curso de las corrientes de agua. Es éste un asunto sobre el que recaerían muchos de los conflictos que reflejan los documentos de la época y territorio que son objeto de este estudio. La escasez de los recursos hídricos compelía, en no pocas ocasiones, a que quienes tenían fácil acceso a los mismos intentaran acapararlos en su beneficio, con el subsiguiente perjuicio de otros interesados en aprovecharse de ellos, los cuales se veían injustamente desposeídos de su derecho. Si se llevaban a cabo obras que impidieran el libre flujo del agua por los cauces acostumbrados, los infractores deberían sufrir el derribo de las mismas ${ }^{8}$.

En cuanto a la obligación general que tienen los propietarios y usuarios de los terrenos ribereños de mantener los cauces de aguas en condiciones óptimas para el curso de las mismas, también las Partidas establecen los términos en que ésta se debe cumplir ${ }^{9}$. Se trata de una materia de enorme

${ }^{6}$ Ibid., 3, 28, 8: «Molino ni canal ni casa ni torre ni cabaña ni otro edificio ninguno no puede hombre hacer nuevamente en los riso por los cuales los hombres andan con sus navíos, ni en las riberas de ellos, porque se embargase el uso comunal de los hombres Y si alguno lo hiciese allí de nuevo o fuese hecho antiguamente de los que viniese daño al uso comunal, debe ser derribado; y no sería gustosa cosa que el provecho de todos los hombres comunalmente se estorbase por el provecho de algunos».

${ }^{7}$ Ibid., 3, 28, 9: «Apartadamente son del común de cada ciudad o villa las fuentes y las plazas donde hacen las ferias y los mercados, y los lugares donde se juntan a concejo y los arenales que están a las riberas de los ríos [...] y todo hombre que fuere allí morador puede usar de todas estas cosas sobredichas, y son comunalmente a todos, tanto a los pobres como a los ricos. Mas los que fuesen moradores de otro lugar no podrían usar de ellas contra voluntad y prohibición de los que morasen allí».

${ }^{8}$ Ibid., 3, 28, 13: «Como se pueden derribar las canales que los omnes fazen nuevamente en sus casas para entrar las aguas quando resciben daño dellas sus vecinos [...] otrosi los valladares, porque estorbasen las aguas de yr por los logares por do suelen venir a las heredades».

9 Ibid., 3, 28, 15: «Corriendo aguas por heredades de muchos, maguer que ninguno dellos non faziese lavor porque la estancase, si el agua por si naturalmente lo fiziere, dejan- 
importancia en el territorio madrileño. La mayoría de las normas agrarias de carácter local analizadas, especialmente las relativas a las plantaciones de lino, cultivo muy extendido en la región durante el siglo XvIII, hacen alusión al susodicho deber de mantener limpios los cauces por donde discurrían las aguas, en consonancia con lo que también disponían las Partidas.

Esta legislación generada en el siglo XIII, como se ha dicho, es la plasmación de los principios procedentes del Derecho romano a través del Derecho común. Su espíritu, en el caso concreto de Castilla, conseguiría traspasar la barrera de los siglos para insertarse en el Derecho recopilado vigente durante toda la Época Moderna, si bien es cierto que el crecimiento exponencial del poder regio modularía la consideración inicial de los bienes que en un principio se consideraban de uso o de dominio público, siempre en beneficio de la Corona.

Aun teniendo en cuenta lo anterior, la legislación alfonsina permanecerá como la única referencia de carácter territorial que desciende a entrar en materia de aguas dentro del territorio castellano.

La falta de concreción de esta normativa traería como consecuencia que en etapas posteriores los pleitos por razón de los aprovechamientos hídricos se multiplicaran notablemente, pues nunca quedó zanjada de forma definitiva la naturaleza pública o privada de esos recursos, así como su carácter de regalía ${ }^{10}$.

Algún autor ha puesto de relieve el hecho de que los redactores de las Partidas no estaban especialmente preocupados en dilucidar la titularidad de las aguas, sino en regular su aprovechamiento ${ }^{11}$. Coincide con esta afirmación Gallego Anabitarte, para quien las Partidas no declaraban todas las corrientes de agua como bienes de uso público, según lo hicieran los romanos (aqua profluens), sino que se limitaban a declarar de uso común todas las procedentes de las lluvias y los ríos aptos para la navegación ${ }^{12}$.

do fustes, o cieno o piedras [...] de manera que destajase el agua, e la sacare del lugar por do solía correr $[. .$.$] se sintiere algún vezino por agraviado [...] pueda apremiar a aquel en cuya$ heredad fizo el agua el estanco [...] o que lo alimpie o que lo deje a el fazer [...] pero si fuera agua que perteneciere a muchos, cada uno en la frontera de su heredamiento es tenudo de ir a yudar a enderezarla, de manera que vaya el agua por do solía».

${ }_{10}$ Francisco Javier FerReIRo Pérez, «Aguas privadas, aguas públicas. Tensión normativa en la Historia», Revista de Obras Públicas. Órgano Profesional de los Ingenieros de Caminos, Canales y Puertos, núm. 3533 (2012), pp. 43-52.

${ }^{11}$ Francisco Meaño, Régimen legal de las aguas en Venezuela, Caracas, 1957, p. 19, defiende que Las Partidas no regulaban el derecho de propiedad sobre las aguas, sino el derecho al aprovechamiento.

12 Alfredo Gallego Anabitarte et al., El Derecho de Aguas en España, t. I, Madrid, MOPU, 1986, p. 131. 
Sin embargo, otras corrientes menores, como arroyos y manantiales, eran tradicionalmente consideradas como bienes sobre los cuales podía ejercitar su dominio el propietario del terreno donde nacían, si bien con las limitaciones derivadas de los derechos adquiridos de otros o del hecho de abastecer de agua a una población, previo reconocimiento de tales derechos por parte del citado propietario del predio en que mana la fuente que luego discurre por algunas fincas ajenas ${ }^{13}$.

Otro elemento jurídico que se ha de tener en cuenta a la hora de abordar estas materias es el Derecho recopilado de la Época Moderna. Si pueden resultarnos escasas las leyes insertadas en las Partidas sobre la materia que nos ocupa, menos incluso son las disposiciones que se incluyeron en las Recopilaciones castellanas alusivas a la forma en que se ha de llevar a cabo el uso del agua en sus distintas versiones.

Dentro de la Novísima Recopilación de 1805, donde se incorporaron la mayoría de las leyes que fueron surgiendo a lo largo de la Época Moderna, no encontramos tampoco ninguna disposición alusiva a la entidad de las aguas como bien jurídico. Al igual que sucedía en las Partidas, tan sólo hallamos normas que aluden a su aprovechamiento de modo tangencial cuando se trata de algunas materias tales como, por ejemplo, los repartimientos entre los vecinos de los pueblos ${ }^{14}$, el régimen jurídico de las poblaciones ${ }^{15}$, o sobre las minas y los pozos de sal ${ }^{16}$. También se añadieron otras referentes a las Reales Acequias y los denominados «novales», que eran los beneficios procedentes de terrenos que, siendo originariamente de secano, pasaban a ser de regadío al verse fertilizados por la construcción de las mencionadas acequias.

La Iglesia participaba también de esos rendimientos a través de los diezmos. Los pontífices concedieron a los monarcas ciertos derechos de carácter fiscal sobre ellos ${ }^{17}$. Ese reparto de beneficios obtenidos a partir de

${ }^{13}$ Los códigos españoles concordados y anotados, op. cit. las Siete Partidas, 3, 31, 5: «Ganada habiendo hombre la servidumbre de traer agua para regar su heredamiento de fuente que naciera en heredad ajena si después el dueño de la fuente quisiese otrorgar a otro poder para aprovecharse de aquella agua non lo pueda fazer sin consentimiento de aquel a quien primer fue otrogada la servidumbre della. fueras ende si el agua fuese atanta que abundase al heredamiento de ambos».

${ }^{14}$ Los códigos españoles concordados y anotados, op. cit., t. VIII, Novísima Recopilación de las Leyes de España, t. II, que contiene los libros quinto, sexto y séptimo, Madrid, 1850, libro VI, título 22.

${ }^{15}$ Ibid., libro VII, títulos 2, 17, 22, 24 y 30.

16 Ibid., libro IX, título 19.

${ }_{17}$ Ibid., libro III, título 10, leyes 7-10, sobre reales acequias, y libro 1, título 6, notas 5 y 6, sobre los novales, así como el título 7, que trata «De los dos novenos, ó tercias Reales de 
los nuevos regadíos trajo como consecuencia no pocas controversias entre las jerarquías eclesiásticas y la Corona. Uno de esos conflictos le costó el cargo al juez subdelegado que se ocupaba de ejecutar los diezmos procedentes de los novales ${ }^{18}$.

Así pues, seguirían siendo las Partidas, en su condición de Derecho general supletorio para la Corona de Castilla, el texto que incidiría con mayor intensidad en lo tocante a los usos y aprovechamientos del agua durante toda la Edad Moderna.

Existía un escalón normativo intermedio entre las normas recopiladas y el texto alfonsino, escalón que ostentaba la mayor trascendencia fáctica, que no jerárquica, a la hora de regular el aprovechamiento de los recursos hídricos por ser el que desarrollaba de forma pormenorizada las prescripciones a que debían atenerse los súbditos. Nos referimos a las disposiciones señoriales y locales.

Ello se debe, probablemente, a que a lo largo de la Baja Edad Media y de Edad Moderna los concejos y los señoríos adquirieron en buena medida la potestad normativa referente a estas materias y a otras muy diversas por dejación de la Corona castellana, de manera que es en los cuerpos de leyes con carácter local o de ámbito territorial reducido donde preferentemente debemos dirigirnos para localizar las disposiciones alusivas a los usos y aprovechamientos del agua en todas sus versiones y de manera pormenorizada.

De ese modo, si bien ya en el siglo XVIII los órganos del poder central tuvieron una enorme importancia en lo tocante al reparto del agua, ello se debe a que se erigieron no tanto en legisladores sobre la materia, sino en árbitros que dirimían las muchas controversias surgidas entre señoríos, poblaciones y particulares.

Cada vez que se planteaba un conflicto, el primer paso para solventarlo consistía en la averiguación de la tradición jurídica afianzada en la región o comarca donde surgía dicha controversia. Ello no deja de suponer una cierta corruptela del sistema de aplicación del Derecho en la Corona de

los diezmos», que eran derechos que podían cobrar los reyes para su real patrimonio a partir de lo que se recaudara en concepto de diezmos en virtud de bulas apostólicas. Ello se estableció por Felipe II en pragmática de 30 de marzo de 1565: «Por quanto las tercias, que son los dos novenos de todos los frutos, rentas y otras cosas que en estos nuestros reynos e diezman, son nuestras y de la nuestra Corona y Patrimonio Real, y pertenecen á Nos por concesiones y gracias Apostolicas».

${ }^{18}$ Ibid., libro I, título VI, «De los diezmos y novales», ley 13. Carlos III, por resolución a Consejo de 23 de noviembre de 1765 y cédula del Consejo de 21 de junio de 1766: «El Juez executor de la bula de novales cese; y se reponga todo lo obrado». 
Castilla, pues, aunque debería observarse escrupulosamente la prevalencia del Derecho escrito sobre el consuetudinario a partir del Ordenamiento de Alcalá de 1348, lo cierto es que los documentos judiciales que se conservan en materia de aguas dentro de la región madrileña demuestran la importancia de las costumbres arraigadas en materia de aguas a la hora de resolver un pleito. Para su mejor averiguación y constatación se solían recabar los testimonios aportados por los labradores más ancianos de las poblaciones implicadas en el procedimiento judicial.

\section{LAS NORMAS DE CARÁCTER LOCAL Y SEÑORIAL}

En este punto hay que distinguir varios ámbitos normativos y jurisdiccionales.

Se intentaba, con carácter general, que las autoridades con cierta ascendencia directa sobre los individuos o los entes colectivos en conflicto asumieran las riendas del proceso conducente a la solución del mismo. De ese modo, nos encontramos con que en la más primaria de las instancias administrativas donde se movían los intereses en torno al agua, es decir, en el ámbito municipal, las autoridades concejiles ostentaban la potestad normativa y jurisdiccional en tales materias.

A medida que la población se incrementaba en las poblaciones castellanas, las necesidades de agua iban creciendo tanto para el consumo directo como para los riegos en las zonas reservadas a la agricultura. Ello multiplicaba los conflictos al colisionar pretendidos derechos adquiridos por los usuarios del agua. Ante la carencia de grandes ríos en la zona, los habitantes del territorio madrileño le otorgaron desde siempre gran importancia a las corrientes fluviales de carácter menor. Éstas eran siempre motivo de preocupación tanto para las autoridades locales como para los diversos señoríos laicos y eclesiásticos que irían apoderándose del territorio a lo largo del Antiguo Régimen.

Las normas que se observaban a la hora de regular los usos del agua tenían un doble carácter. Por una parte encontramos un contingente considerable de ellas dentro de los textos jurídicos locales, particularmente en las ordenanzas municipales que se fueron formando a partir de finales de la Edad Media y que evolucionaron durante la Época Moderna. En lo tocante a la regulación de los temas relacionados con el uso y aprovechamiento de los recursos naturales, entre ellos las corrientes de agua, algunas prolongaron su vigencia hasta momentos muy avanzados del siglo XVIII. Es importante señalar que todos los organismos de poder durante el Antiguo Régi- 
men les concedían a estos cuerpos legales una extraordinaria importancia, sin duda por el arraigo popular que tenían.

A tenor de los documentos, tanto los particulares como las autoridades les reconocían validez y procuraban guardar esas antiguas ordenanzas en la medida de lo posible. El problema surgía cuando la parte perjudicada por sus prescripciones intentaba neutralizar su vigencia alegando haber caído tales normas en desuso debido al transcurso de los años o a la falta de confirmación por parte del órgano de poder que debía confirmarlas y mantenerlas, de ese modo, con vida. De ello hay algunos ejemplos en la región madrileña, donde se pueden encontrar algunos textos en cuya exposición de motivos se expresa específicamente que fueron presentados para su confirmación después de un tiempo de relativo letargo con el fin de evitar los citados inconvenientes ${ }^{19}$.

No son muchas, por desgracia, las ordenanzas municipales promulgadas en territorio madrileño durante las aludidas etapas históricas que se conservan en la actualidad. Baste decir, para resaltar la importancia de las mismas, que, si bien hunden la mayoría de ellas sus raíces en la etapa medieval y los albores de la Edad Moderna, algunas se siguieron redactando a lo largo de los siglos XVI y XVII. Mención especial dentro del territorio madrileño merecen las de Montejo de la Sierra, que se elaboraron en el siglo $\mathrm{XIX}^{20}$. De las anteriores, en no pocas ocasiones nos consta su vigencia ya bien avanzado el siglo XVIII ${ }^{21}$.

A veces tenemos acceso al conocimiento de tales cuerpos normativos gracias a que se transcribieron total o parcialmente al hilo de los pleitos entre particulares o entre poblaciones que luchaban por la exclusividad en el disfrute de algunas corrientes fluviales, generalmente convecinos que desviaban las mismas en su provecho. Tal es el caso del pleito larguísimo y nunca definitivamente resuelto entre el concejo madrileño y el señorío de El Real de Manzanares juntamente con algunas de sus poblaciones ${ }^{22}$.

19 AHN, Consejos, leg. 35127, 1, «Ordenanzas de riegos en Cerceda», fols. 5-6: «El Concejo del dicho Lugar de muchos años y tiempo a esta parte ha tenido y tiene sus Hordenanzas y constituciones usadas y guardadas para la manera de se regar y gobernar zerca de el agua que tienen y de la manera de regar los linos y de su dehesa y exido y de las penas de las cartas de los montes y dehesas zerradas [...] y porque las dichas hordenanzas no estan confirmadas de vuestra señoria aunque son utiles y provechosas para la governazion y sustentamiento del pueblo, algunos de nuestros vecinos quando no les esta bien de las guardar nos las contradicen y nos causan sobre ellas pleitos y gastos».

${ }^{20}$ Matías Fernández García, Fuentes para la Historia de Buitrago y su tierra, vol. 1, Madrid, 1966, p. 82.

${ }^{21}$ Ibid., p. 145.

22 Archivo General de Simancas, Registro General del Sello, leg. 149510. En este 
Por otra parte, como se ha señalado, no conviene desdeñar la importancia de la tradición consuetudinaria en estas materias. También de los autos relativos a los pleitos entre distintos pueblos o entre particulares que habitaban las comarcas madrileñas se desprende el enorme respeto que merecían tales costumbres alusivas al reparto del agua, ancestrales muchas de ellas, hasta el punto de observarse escrupulosamente en épocas bastante tardías los denominados «relojes de riego», basándose éstos en los puros fenómenos naturales, aludiendo, por ejemplo, a las horas de la salida y la puesta del sol, o al instante en que éste se oculta detrás de tal o cual cumbre de alguna montaña, al momento del día en el que una persona que goza de una agudeza visual normal no puede distinguir el valor de una moneda por falta de luz natural, etcétera ${ }^{23}$.

Conocemos bastantes de esas costumbres antiquísimas gracias a que muchas de ellas se insertaron en los textos legales de carácter local que se elaboraron a lo largo de la Época Moderna ${ }^{24}$. De su extraordinario arraigo en el seno de la población rural madrileña nos da idea la inclusión sistemática de las mismas en dichos cuerpos normativos pertenecientes a épocas en las que ya se había generalizado el uso de los relojes mecánicos.

También todas esas tradiciones eran tenidas en cuenta por los distintos juzgadores y autoridades a la hora de decidir las controversias surgidas en torno al agua. Tanto si tales costumbres habían pasado a formar parte del acerbo legal compuesto por fueros y ordenanzas, como si se hallaban exclusivamente vivas gracias a su observancia inveterada por los súbditos sin que se hubieran llegado a poner por escrito, lo cierto es que los documentos judiciales del siglo XVIII dan fe de la permanente indagación por parte de los juzgadores para desentrañar su existencia y demostrar o rebatir su vigencia.

expediente ya se pone de manifiesto la existencia de litigios por diversos aprovechamientos en la zona fronteriza entre el señorío de El Real de Manzanares y el concejo madrileño en el siglo XVI. En lo referente al aprovechamiento del agua de forma específica, el mejor exponente lo encontramos en el pleito que mantuvieron dichas entidades durante la primera mitad del siglo XviII, cuyos autos obran en el Archivo Histórico Nacional, Consejos, leg. $35127,1$.

${ }_{23}$ Matías Fernández García, Fuentes para la Historia de Buitrago y su tierra, op. cit., p. 89. Vid. Ordenanzas de Villavieja de 1485: «Otrosi hordenaron mas allende de lo hordenado que a las horas que an de estar en saliendo el sol en los çerezos e en poniéndose el sol en los çerezos» (p. 99); Ordenanzas de Piñuécar de 1593: «Lunes desde que sale un luçero antes quel del alba y se pareze enzima d ela dehessa de madarcos casi al camino que va a horcajuelo».

${ }^{24}$ Ibid., p. 81. Señala Matías Fernández que «las de Buitrago son de 1534 y recogen por escrito las costumbres antiguas». 
A veces eran los propios órganos centrales de poder quienes concedían a ciertas poblaciones ordenanzas para regular el ámbito rural, cual es el caso de unas que fueron dadas por Carlos III el 10 de febrero de 1771 para la población de Alcalá, aprobadas por el conde de Aranda y que se refieren a aspectos relacionados con los aprovechamientos naturales ${ }^{25}$. Pero lo más habitual era que se fueran conformando dichas ordenanzas como producto de la tradicional autonomía normativa de los municipios.

Mención aparte merece, en este punto de la regulación aplicable en el territorio madrileño en materia de aguas, el asunto relativo a la enorme incidencia que tuvo en el espacio madrileño la proliferación de los Reales Sitios, pues éstos serían objeto de una legislación específica directamente generada e intervenida por la Corona. Tampoco son muchas las disposiciones relativas al uso, transcurso y aprovechamiento de las corrientes de agua en estas regias reservas que pasaron a los textos territoriales, pues los monarcas prefirieron insertarlas en cuerpos de ordenanzas específicos para cada uno de esos espacios privilegiados. Así, espacios rurales pertenecientes a lo que hoy es la provincia y Comunidad Autónoma de Madrid, tales como los que rodean el Monasterio de El Escorial, el palacio de Aranjuez, El Pardo, etc., gozarían de unos estatutos jurídicos específicos que restringían todos sus aprovechamientos de manera que redundaran fundamentalmente en beneficio de la Corona.

En este punto cabe hacer alusión al acotamiento sistemático de las corrientes de agua que naturalmente discurrían por tales territorios, así como a determinadas obras hidráulicas que se llevaron a cabo por iniciativa de los reyes entre los siglos XVI y XVIII. Las denominadas Reales Acequias y ciertos embalses destinados sobre todo al riego de sus territorios aledaños y al abastecimiento de los Reales Sitios fueron objeto de una meticulosa regulación por parte de los monarcas, además de una fuente de ingresos para el erario público a causa de los derechos que debían satisfacer los súbditos que se beneficiaban de tales corrientes de agua y regadíos ${ }^{26}$. Se trata de territorios generalmente ricos en acuíferos, de ahí que los reyes los eligieran con el fin de que pasaran a formar parte de su patrimonio y dominio directo. Solían ser ricos en especies piscícolas y cinegéticas, precisa-

25 José García Saldaña, Documentos olvidados, Alcalá de Henares, 1986, p. 21.

${ }^{26}$ Citaremos como ejemplos de estas disposiciones específicas, de las cuales nos ocuparemos pormenorizadamente más adelante, una Real Cedula de Su Magestad por la qual a consulta del Consejo, en Sala de Justicia, se sirve incorporar en la Real Corona la azequia de la Vega de Colmenar de Oreja, de 1771, o Las reglas baxo las quales el banco ha de desempeñar a construccion del canal de Guadarrama hasta Madrid, de 1786. 
mente por la abundancia de aguas. Además, sus particularidades así como su emplazamiento, garantizaban que las estancias de los cortesanos en ellos resultaran confortables, sin las penurias que sufría el común de los súbditos en tiempo de sequía.

En esos territorios nos encontramos con cuerpos jurídicos en forma de Reales Ordenanzas destinados a establecer regímenes peculiares exceptuados de los que se aplicaban con carácter general por parte de las autoridades directamente dependientes de la Corona o por parte de concejos y señoríos. A pesar de que generalmente aparecen denominados con el título de Ordenanzas, su configuración y contenido distan ampliamente de los que son propios de las ordenanzas municipales ${ }^{27}$, compartiendo con éstas, eso sí, su ámbito territorial reducido, aunque no meramente local. En cuanto a los destinatarios de dichas normas, tales cuerpos legales afectaban a los vecinos de las poblaciones que radicaban dentro del territorio acotado ${ }^{28}$.

Otro elemento que, sin tener en teoría carácter estrictamente normativo, nos consta fue profusamente tenido en cuenta a la hora de solventar los pleitos en torno al agua dentro de la región madrileña, era el acerbo que componían las sentencias dictadas por las autoridades judiciales en momentos anteriores al conflicto, cuando éstas se habían pronunciado sobre ese particular en ciertas poblaciones de la misma comarca. Sabemos, por ejemplo, que en el pleito que se sustanció durante el siglo XVIII entre la Villa de Madrid y El Real de Manzanares, los órganos jurisdiccionales solicitaron, entre otros elementos probatorios, que las partes aportaran las sentencias que se conservaran en los archivos municipales y que hubieran sido dictadas en años o siglos anteriores siempre que estuvieran relacionadas con los aprovechamientos del agua ${ }^{29}$. La jurisprudencia sentada de ese

${ }^{27} \mathrm{M}^{\text {a }}$ de los Ángeles Toajas Roger, «Las Ordenanzas de Aranjuez en los siglos XVI a XVIII: referentes documentales para la historia y la arquitectura del Real Sitio», Anales de Historia del Arte, núm. 6, UCM, 1996, pp. 85-121. La autora señala en la p. 87 algunas diferencias con las ordenanzas municipales en el caso concreto de las promulgadas para el Real Sitio de Aranjuez. Sin embargo, apunta que cuando a partir de 1757 se desvinculó la propiedad de las casas del servicio de la corte, se dictaron ordenanzas similares a las propiamente municipales para materias tales como el orden público.

${ }^{28}$ Citaremos a modo de ejemplo el Reglamento y Ordenanzas que deben observar los vecinos estantes y habitantes en las Villas de San Martin de la Vega, Ciempozuelos, Seseña, Añover, Villaseca, Magan, Mocejon, Velilla, y demas que en sus terminos y en todos los que corre la Real Acequia de Xarama, tienen tierras, y possessiones que se pueden beneficiar con el riego, par que este sea en utilidad del comun y de los interesados a quienes comprehenda y le ayan de tener de la referida Real Acequia, Impresas en Madrid en 1740.

${ }_{29}$ AHN, Consejos, leg. 35127, 1, fols. 33-34: «E visto dos sentencias presentadas por parte del dicho cauildo de la Zerezeda la una que fue dada por Alfon Perez Alcalde maior que era a la sazon en el dicho Real por el Ynfante Don Fernando que Dios perdo- 
modo por árbitros y tribunales oficiales se insertaba en la práctica, también de forma espuria como sucedía con la costumbre local, dentro de un ordenamiento que teóricamente la rechazaba como fuente del Derecho.

De esta manera quedaba dibujado el esquema jurídico sobre el que se sostenía todo el entramado de normas relativas a los usos y aprovechamientos hídricos en el territorio madrileño durante el Antiguo Régimen y, especialmente, durante la etapa ilustrada.

Como examinaremos a continuación, múltiples y diversos serían los aspectos regulados en las normas alusivas a la utilización del agua en todas sus versiones dentro de las diferentes comarcas madrileñas. Desde los usos agrícolas de la misma hasta su consumo directo por parte de la población, tanto en estado líquido para beber o limpiar sus cuerpos y ropas, como en forma de nieve o hielo, pasando por la regalía de las salinas, todo en torno a tan esencial elemento lo encontraríamos regulado a lo largo y ancho de diferentes cuerpos legales hasta que la obsesión unificadora del Derecho, generada a raíz de la expansión de las doctrinas positivistas, diera como resultado en España la elaboración de una célebre Ley de Aguas de larguísima vigencia y considerable calidad técnica, fruto de la concienzuda labor de los juristas codificadores del siglo XIX.

\section{PANORÁMICA SOBRE LAS CIRCUNSTANCIAS ESPECÍFICAS DE LA REGIÓN MADRILEÑA COMO SEDE Y ENTORNO DE LA CORTE}

No se trataba de una nueva circunstancia. La Villa de Madrid se había transformado en corte de la monarquía española de forma permanente en 1561, año en que Felipe II comunica al concejo madrileño el traslado de la capital, antes con sede en Toledo.

Parece ser que tal decisión tiene mucho que ver con la climatología y el abastecimiento hídrico madrileños, pues Toledo, lugar en que había radicado la corte con anterioridad durante un breve periodo de tiempo, experimentaba aún más los rigores y extremos propios del clima continental,

ne, y consentida por parte de los dichos Cavildos segun que en ella se contiene dada por el dicho Alcalde en razon de la auenenzia del agua (al margen se lee: primera sentencia antigua año de 1334, y más abajo: segunda sentencia antigua año de 1394. Sin embargo, en el texto del documento pone: "era de mil y treszientos y treinta e quatro años", luego la sentencia más antigua sería de 1296) [...] que viene por el arroio que dizen de la Garganta del Arroio del Pez». 
además de que la profunda ubicación del río Tajo hacía bastante costoso el acceso a la única corriente de agua con que contaban los toledanos.

Lo cierto es que en el siglo XVIII Madrid ya se ha afianzado hace tiempo como Villa y Corte, con los inconvenientes y ventajas que ello suponía para sus habitantes no sólo en el casco urbano de la capital, sino también para todos los territorios circundantes.

La decisión inicial trajo consigo el establecimiento en suelo madrileño de una serie de reservas para el monarca, los ya aludidos Reales Sitios, en los cuales el uso y aprovechamiento del agua jugaba un papel fundamental, al igual que ocurría con otras fuentes de riqueza tales como la caza, la pesca, etc.

Tales riquezas serían en esas zonas aprovechadas de manera privilegiada por los cortesanos adscritos a tales reservas, sin olvidar a los súbditos que en ellas habitaban y que, por ese mero hecho, se constituían en sujetos de derechos y obligaciones diferentes del resto de los pobladores del espacio madrileño. A tales efectos fueron creados cuerpos legislativos específicos para regir en los sitios reales, las ya aludidas ordenanzas destinadas a excluir los bienes y las aguas que radicaban en el territorio acotado del uso generalizado por parte de los súbditos que en ellos habitaban.

En el siglo XVIII ya podemos contabilizar bastantes de estas zonas acotadas, algunas de ellas incluidas en el propio alfoz de la capital. También merecen especial atención las que se insertaban dentro de las comarcas serranas o de la llanura de la región madrileña. Eran los territorios en los que se hallan ubicados los palacios de El Pardo o Aranjuez, así como el Monasterio de El Escorial. Resultan significativos los dos últimos por el especial significado que en ellos tuvieron los aprovechamientos hídricos y porque El Pardo ha sido asimilado como distrito perteneciente a la capital en 1950.

Contando con el territorio aledaño al Real Monasterio de El Escorial y con el asimilado al palacio de Aranjuez, por no mencionar todos los espacios propios del monarca en el alfoz municipal de Madrid, la corte disfrutaba de una gran variedad de climas, paisajes, servicios y prestaciones sin necesidad de abandonar el territorio madrileño ${ }^{30}$.

Todos esos espacios fueron desarrollándose muchas veces a pesar de los concejos colindantes, así como de los señoríos circundantes y conveci-

30 Fernando Chueca Goitia, «Los Reales Sitios en torno a Madrid», Reales Sitios, año 26, núm. extraordinario, 1989, pp. 47-56. En la p. 47 el autor se refiere al Monasterio de El Escorial como «un pequeño universo en miniatura, un microcosmos». 
nos, produciéndose entre todos ellos y en no pocas ocasiones graves conflictos con motivo de los múltiples aprovechamientos y las jurisdicciones diversas que hacían valer su poder dentro de las comarcas de la actual Comunidad Autónoma.

Además de los espacios propiamente palaciegos, extendían los reyes sus poderes casi omnímodos a ciertas corrientes de agua canalizadas por medio de grandes obras hidráulicas llevadas a cabo con el patrocinio de dichos monarcas desde el siglo Xvi y que alcanzan sus máximos exponentes durante el siglo XVIII, como es el caso de la Real Acequia de Colmenar de Oreja o de la Real Acequia de Jarama, por citar algunas de ellas. Esos cursos acuáticos estaban encaminados a finalidades diversas tales como el uso directo para consumo o limpieza, el riego de las zonas tanto agrícolas como ornamentales existentes en torno a los palacios, e incluso a la navegación de personas y mercancías.

Otras de esas obras irían encaminadas a la retención de las aguas que circulaban por el territorio madrileño en época de lluvias por medio de la construcción de presas y embalses, como en el caso del llamado Mar de Ontígola, en los terrenos aledaños a Aranjuez, ideado por los ingenieros de Felipe II con el fin de abastecer las necesidades de su palacio en dicha localidad.

La creación de tales obras públicas implicaba una ingente inversión de tiempo y dinero que los reyes intentaban recuperar mediante el establecimiento de unos tributos destinados a ser satisfechos por los súbditos que, potencialmente o de facto, podían beneficiarse de las corrientes de agua que se veían modificadas a través de tales trabajos de ingeniería.

En suma, actividades relacionadas con el uso de las corrientes de agua, tales como los riegos, la pesca, la instalación de barcas de tránsito, puentes, molinos, presas etc., se hallaban en los Reales Sitios bajo la estricta vigilancia de las autoridades nombradas directamente por los monarcas para la conservación y correcta administración de las mismas, teniendo dichos organismos de poder la jurisdicción directa en todas las materias que se hubieran de dirimir dentro de tales territorios cuando afectaran a los usos del agua e incluso a otros asuntos de índole civil y criminal, todo ello en detrimento de las tradicionales potestades jurisdiccionales de señoríos y concejos, con los conflictos que ello implicaba en el ámbito de la administración de justicia.

La profusión normativa en torno a los emplazamientos regios daría lugar a que se recopilaran y comentaran desde época relativamente temprana las disposiciones alusivas de manera particular a los mismos a partir de la iniciativa de juristas privados. Ése es el caso de la tarea comenza- 
da por Pedro de Cerbantes, alcalde de Casa y Corte y de la Real Junta de Obras y Bosques ${ }^{31}$.

Como puede observarse, el panorama normativo en la región madrileña durante el siglo XviII dista mucho de ser monocromático y uniforme. Por ello es interesante abordar el tema relativo a la forma en que interactuaban las distintas autoridades que ostentaban las potestades normativa y jurisdiccional a la hora de generar y aplicar disposiciones que pudieran solucionar los numerosos conflictos generados entre los habitantes madrileños con motivo de los aprovechamientos y usos del agua que discurre por el territorio.

\section{ORGANIZACIÓN POLÍTICO-ADMINISTRATIVA PARA LA GESTIÓN DE LOS RECURSOS HÍDRICOS DURANTE EL ANTIGUO RÉGIMEN}

Nuevamente corresponde distinguir entre diversos ámbitos de poder a la hora de abordar el tema que nos ocupa.

Por una parte, encontramos varios órganos directamente dependientes de la Corona castellana encargados de gobernar las aguas que discurrían por el territorio madrileño, unos colegiados y otros unipersonales. A ellos correspondía la superior instancia jurisdiccional cuando los administrados apelaban las decisiones judiciales dictadas por instancias inferiores, es decir, concejos y señoríos. Por otro lado, ostentaban generalmente la jurisdicción directa sobre los asuntos relativos a los Reales Sitios y, cómo no, a los problemas que pudieran surgir relacionados con las obras hidráulicas iniciadas o llevadas a cabo bajo la directa iniciativa de la Corona.

Por otro lado, hallamos que las autoridades de los concejos también tenían mucho que decir en lo referente al modo de gobernarse los aprovechamientos y usos del agua que nacía en sus alfoces o que circulaba por ellos. Dichas autoridades salían al paso de los aspectos más inmediatos y cotidianos, tanto a la hora de generar normas relativas a las aguas como constituyéndose en la primera instancia jurisdiccional en caso de conflictos sobre la materia.

Por último, el estamento señorial, de gran impronta e influencia en la región de Madrid, estaría llamado a ejercer un nivel intermedio de poder

${ }^{31}$ Recopilacion de las Reales Ordenanzas y Cedulas de los Bosques Reales del Pardo, Aranjuez, El Escorial, Balsain y otros: Glossas y commentos a ellos. Por Pedro de Cerbantes que lo empeço, y don Manuel Antonio de Cerbantes, su sobrino, que lo continuo y concluyo, Madrid, 1678. 
entre los concejos y el monarca. Éste les había atribuido desde antiguo diversas potestades dentro de sus territorios, de modo que a ellos tocaba, en no pocas ocasiones, el control de las disposiciones locales dentro de sus señoríos a través de la aprobación y confirmación de ordenanzas municipales y del ejercicio de sus prerrogativas de jurisdicción. Éstas se ponen principalmente de manifiesto cuando las controversias en torno al agua afectaban a varios concejos radicados en su territorio.

Hechas estas indicaciones previas, vamos a abordar a continuación un examen panorámico donde se tratará acerca de quiénes eran esos órganos de poder, independientemente de que su análisis sistemático y pormenorizado podría ser objeto de un trabajo mucho más amplio. Tales organismos podrían asumir un protagonismo especial dependiendo del ámbito jurídico en el cual ejercieran su actividad.

Por lo que respecta a los órganos dependientes del monarca con competencias en materia de aguas dentro del territorio madrileño, el Consejo Real y la Audiencia y Chancillería de Valladolid, al igual que en lo que atañe a otras muchas materias, tenían encomendada la superior tutela de cuantas controversias pudieran surgir en torno al reparto y uso de las aguas, de manera que se constituían en órganos jurisdiccionales a los que llegaban los litigios que no se hubieran solventado por medio de las decisiones judiciales generadas por las autoridades locales y señoriales, o mediante acuerdos, en algunos casos de carácter privado y extrajudicial, realizados entre ellas ${ }^{32}$.

A los efectos del presente trabajo, resulta más interesante aludir de manera especial a las personas y organismos que ostentaban competencias específicas en materia de aguas.

Llegado este punto, conviene precisar que la mayor parte de los documentos ilustrativos sobre las competencias atribuidas a los órganos de la Administración central en las distintas comarcas madrileñas se centran, como es lógico, en los territorios asimilados al real patrimonio.

Ya se advirtió con anterioridad que la tradición jurídica concedía a las autoridades locales y señoriales de los diferentes territorios la tutela y

32 Se trata de un pleito civil por agua de riego que llegó en apelación a la Real Chancillería tras el auto dictado por la justicia ordinaria de dicha villa (AR, leg. 96070, 16, Loeches, 1790). Llega hasta el Consejo Real una controversia entre unos conventos de monjas y el concejo de dicha localidad acerca de sobre quién recaería el pago de unas obras necesarias para reparar unos destrozos ocasionados en las minas de agua que abastecían la población y el molino aceitero. Las monjas se negaban a contribuir. Finalmente el concejo recibe autorización del Consejo Real para realizar las obras obligando a los conventos de religiosas al pago de la parte correspondiente [AR, leg. 96316, 188; 96137, 6, y 96255, 90, Loeches, Órdenes (febrero de 1768)]. 
jurisdicción sobre todos los asuntos cotidianos relacionados con los usos y repartos de los acuíferos que se generasen o discurriesen por ellos. Ése es el motivo por el cual las alusiones a ciertas autoridades dependientes de la Corona con atribuciones específicas en esa materia las solemos hallar en los documentos relativos a las poblaciones asimiladas de algún modo a esos terrenos acotados por el monarca y destinados a usos específicos que redundaran en beneficio directo de la real casa o, en su caso, a las grandes obras de abastecimiento y regadío llevadas a cabo por iniciativa del rey.

Así pues, la actividad de esos ministros asimilados a los órganos de gobierno centrales se pone de manifiesto en los documentos relativos a poblaciones madrileñas tales como Arganda, Loeches, San Martín de la Vega, etc.

Una vez más, conviene hacer alusión a la importancia de los Reales Sitios y Acequias en territorio madrileño. En ellos se produjo, sobre todo durante el siglo XVIII, una gran proliferación de cargos públicos designados por el rey para ejercer su autoridad en los entornos específicos de los palacios y canales asimilados a la monarquía de forma directa.

El rey expedía en ocasiones carta-orden a través de decretos del Consejo Real cuando se trataba no tanto de dirimir controversias como de impulsar obras públicas iniciadas por iniciativa regia ${ }^{33}$. En otros casos, esas provisiones del monarca salían al paso de algunas situaciones difíciles para los súbditos cuando éstos se dirigían al Consejo para solicitar ayuda ${ }^{34}$.

A partir de 1748 , y a raíz de la política borbónica en materia de montes y plantíos, íntimamente relacionada con el desarrollo de los astilleros, el monarca nombraría dos jueces conservadores de montes y plantíos entre los componentes del Consejo Real ${ }^{35}$. Uno de ellos tendría com-

33 Ése es el caso, por ejemplo, de una carta-orden por la que el monarca ordenaba que se juntara el ayuntamiento de Loeches con el fin de tasar unas obras que se debían realizar en unos caces de riego (AR, leg. 96078, 20, 14 de marzo de 1766).

34 A causa de la sequía que asolaba la población de Loeches en 1744, Carlos III expidió real provisión para permitir que los ganados de dicha localidad pudieran ser abrevados en el pilón, como respuesta a la siguiente petición: «Don Carlos por la gracia de Dios [...] a vos la justicia ordinaria de la Villa de Lueches, salud y gracia. Sabed que ante los de nuestro Consejo represento [...] que con motivo de los excesivos calores [...] se hallan los bebederos destinados para los ganados lanares desta villa de lueches tan escasos de agua que los generales sitos en la vega se hallan secos» (AR, leg. 96316, 141).

${ }_{35}$ Nov. Rec., 7, 24, 16. Por cédulas de 7 y 12 de diciembre de 1748 el rey encarga «de la conservación de montes y plantios á dos Ministros del Consejo nombrados por S. M.». Más tarde, un Decreto de 19 de septiembre de 1755 estableció que los dos ministros encargados por el rey del aumento y conservación de montes y plantíos, cada uno en su respectivo distrito, diesen a los corregidores y justicias de su provincia y partidos las órdenes necesarias para la observancia de la Real Ordenanza de Bosques de 1748. Como miembros que eran del 
petencia sobre las veinte (luego ampliadas a veinticinco) leguas en torno a la corte, y el otro sobre el resto del territorio cuando no estuviera directamente afectado por la Ordenanza de los Montes de Marina del mismo año. Aunque la Novísima Recopilación no alude a ello de forma directa, los documentos nos ilustran sobre su obligación de velar en lo tocante al mantenimiento de los cauces de agua en condiciones óptimas para que las corrientes pudieran discurrir adecuadamente. Ello se llevaba a cabo por medio de exhortos dirigidos a las distintas poblaciones por las que transitaban dichas aguas ${ }^{36}$.

Otras autoridades que formaban parte de la Administración central se hallaban involucradas en ciertos asuntos relacionados con el agua, especialmente cuando las poblaciones afectadas se hallaban en los terrenos aledaños a los Reales Sitios o a las Reales Acequias. Cuando se iniciaba expediente municipal de obras para el arreglo de conducciones se requería licencia expedida por el contador mayor e intendente interino de la ciudad en cuya órbita administrativa se encontrara el municipio donde se hubieran de realizar los trabajos ${ }^{37}$.

Puntualmente el rey, por medio de su Real Consejo, nombraba jueces de comisión para que velaran por la correcta ejecución de determinadas obras relacionadas con las corrientes de agua. Tales obras en muchos casos se llevaban a cabo por medio de repartimientos entre los pueblos que se iban a beneficiar de tales construcciones. Dichos jueces se ocupaban de que la recaudación de tales repartimientos se hiciera según el calendario establecido y coordinaban los trabajos de construcción ${ }^{38}$.

Pero, sin lugar a dudas, donde se observa la mayor impronta de las autoridades centrales dentro del territorio madrileño durante el siglo XVIII es en las zonas por las cuales discurren las aguas asimiladas a los Reales Sitios y a las Reales Acequias. Un sinnúmero de organismos, ministros y oficiales fueron creados y designados como encargados de salvaguardar las

Consejo Real, recibirían las quejas y apelaciones en materias de su competencia transmitiéndolas a dicho Consejo, no sin antes obligar a satisfacer las condenas establecidas por autoridades inferiores, sin cuyo requisito no darían curso a tales apelaciones.

${ }^{36}$ Se trata de una licencia concedida por dicho juez conservador para la limpieza del monte y el arroyo (AR, Villamanta, 1769).

37 Así consta en un expediente municipal de arreglo de cañerías (AR, leg. 96255, 92, Loeches, 1780).

${ }^{38}$ Ese juez ejecutor se hallaba encargado de acudir a la comarca afectada por las obras y comunicar a los concejos las provisiones reales del Consejo ordenando realizar los repartimientos correspondientes. En este caso se trataba de construir el puente y calzada de la villa de Uceda en 1755 (AR, leg. 913581, San Martín de la V.). 
disposiciones especiales dictadas para la administración de tales entornos, no pocos de ellos relacionados con los cursos acuáticos, a causa de la abundancia de los mismos en los lugares elegidos por los reyes para su asentamiento y construcción.

Entre esos órganos cabe destacar uno con gran raigambre que venía funcionando desde hacía siglos y que fue instaurado en su día por Carlos I. En 1545 se crea la Junta de Obras y Bosques, que abarcaba todas las competencias relativas al real patrimonio. Ejercía su jurisdicción de forma privativa, sin depender de otros consejos, para todo lo tocante a los edificios y bosques reales, dando las órdenes convenientes para la conservación y aumento de la caza, pesca, hierba y leña de los bosques ${ }^{39}$. Desaparecería ya bastante avanzado el siglo XVIII ${ }^{40}$.

\section{OBSERVACIONES FINALES}

Posiblemente, lo primero que salta a la vista de cualquiera que se aproxime al estudio del régimen de aprovechamiento del agua en las diferentes comarcas madrileñas durante los siglos pasados es la insuficiencia de los recursos hídricos y el aprovechamiento inadecuado de los mismos.

Los extremos propios del clima continental siempre han determinado que los habitantes de la región madrileña hayan tenido que sufrir una excesiva dependencia de la alternancia cíclica entre épocas de sequía y temporadas húmedas a lo largo del año.

Incluso las zonas boscosas de la sierra se secan en verano, desapareciendo durante la etapa estival muchas de las pequeñas corrientes de agua que discurren por ellas en el resto de las estaciones. Por todo ello, al igual que en la actualidad, los territorios que, ya en la etapa constitucional, serían adscritos primero a la provincia de Madrid y luego a su Comunidad Autónoma, experimentarían como problema de fondo la escasez de

39 Alonso NúÑEz DE CASTRo, Sólo Madrid es Corte, Madrid, 1996, ed. facsímil de la original de 1675 , p. 111.

40 Novísima Recopilación, III, 10, 1. Carlos III, Real Decreto de 18 de noviembre de 1768 , titulado «Supresion de la Junta de obras y bosque Reales, y conocimiento de los negocios de estos ramos». De ello se ha ocupado específicamente Francisco Javier Díaz GoNZÁLEZ, «La disolución de la Real Junta de Obras y Bosques en el siglo XVIII», Anuario de la Facultad de Derecho de la Universidad de Alcalá de Henares, núm. 13, Universidad de Alcalá, 2006, pp. 69-82, esp. p. 80. La Real Junta de Obras y Bosques desaparece por Decreto de 18 de noviembre de 1768 plasmado luego en Real Cédula de 24 del mismo mes y año, pasando sus competencias a manos de la primera Secretaría de Estado y de Despacho. 
los recursos hídricos, si bien achacable a ciertos abusos distintos de los que la propician en los tiempos actuales.

Las normas tradicionales castellanas que servían de telón de fondo para solventar o paliar esas deficiencias siempre fueron insuficientes para atajar los conflictos que nacían de la escasez y desaprovechamiento del agua que discurre por la región. Especialmente las disposiciones legales de carácter general promulgadas por los reyes al efecto de poner orden en estas cuestiones nunca fueron lo suficientemente claras como para poder fundamentar soluciones jurídicas firmes e incontrovertibles, por lo cual adquirieron especial protagonismo algunas fuentes del Derecho que, en principio, se hallaban proscritas del panorama castellano, como es el caso de la tradición consuetudinaria y las decisiones judiciales o arbitrales.

La escasez de normas legales es el principal motivo por el que se observa dentro de los documentos de aplicación del Derecho conservados una excesiva proliferación de pleitos que sólo difícilmente y con carácter excepcional se resolvían de manera duradera o definitiva, al no conformarse los perjudicados por los juzgadores con la solución que éstos ofrecían. Las partes en discordia solían recibir sentencias generadas sobre la base de algunas normas consuetudinarias inducidas a partir de ciertos testimonios de personas ancianas, de modo que la falta de leyes específicas servía como pretexto de incumplimiento y reincidencia en los actos objeto de denuncia a quienes no se conformaban con dichas resoluciones judiciales o arbitrales. A causa de todo ello se constata en esos instrumentos la reiteración secular de los conflictos que nacían entre los diferentes municipios de la misma comarca.

Por otro lado, la pluralidad y diversidad de órganos políticos coexistentes en lo que hoy es la Comunidad de Madrid se constituyen en una dificultad añadida a la hora de poner orden en la resolución de los pleitos nacidos del siempre controvertido aprovechamiento de algunas corrientes de agua a menudo de rango menor y estacional.

La capitalidad de Madrid proclamada a mediados del siglo Xvi generó un protagonismo de la Villa y Corte que resultaría claramente nocivo para las poblaciones circundantes a causa de la creciente y exorbitante necesidad de recursos hídricos para abastecer la demanda de sus habitantes desde ese momento y a lo largo de los siglos posteriores.

Son, por ejemplo, repetidos y prolongados en el tiempo los pleitos mantenidos por la ciudad contra las autoridades y poblaciones de El Real de Manzanares, debido a los intentos llevados a cabo por ambas partes para acaparar el caudal del único río que atraviesa la villa madrileña y tam- 
bién de sus afluentes. Se resolvían casi siempre a favor de la capital, residencia de los reyes.

En cuanto a las instancias de poder que coexistían con la realeza dentro de la región madrileña, hay que destacar la importancia de ciertos señoríos que habían ido ganando tierras y poder en la misma a lo largo de la Edad Media y la Época Moderna. Éstos también ostentaban la potestad normativa y de administrar justicia dentro de sus respectivos territorios, lo cual añadía dificultades a la correcta administración de las corrientes hídricas, cuya titularidad siempre se hallaba en entredicho. Lo cierto es que, a juzgar por la documentación que obra en los archivos, se observa una cierta incuria por parte de los órganos de justicia señoriales a la hora de juzgar en litigios entre poblaciones menores cuya resolución no les iba a reportar beneficio alguno a los titulares del señorío ${ }^{41}$.

Si a todo lo anterior le añadimos la circunstancia específica de la región madrileña consistente en que los monarcas emprendieron, sobre todo desde los albores de la Época Moderna, una política de acaparamiento de las riquezas naturales de la zona mediante el establecimiento de los denominados «Reales Sitios», el panorama jurídico del agua en las diferentes comarcas madrileñas estaría llamado a complicarse exponencialmente. Ello llega a su cénit en el siglo XVIII, época en que se emprenden, en unos casos, o se culminan, en otros, las grandes obras hidráulicas que se pusieron en marcha a partir de la iniciativa regia. Se denominaban «Reales Acequias», «Reales Canales», etc., y serían objeto de regulación específica por parte de los reyes a través de una normativa exclusiva para ellos y los terrenos circundantes a las susodichas construcciones.

Para acabar de complicar el panorama del agua en la zona objeto de estudio nacerían desde el siglo XVIII y se desarrollarían en el XIX ciertos hábitos de la población ciudadana, que no campesina, tendentes a valorar de manera especial el aspecto higiénico del entorno urbano en que se desenvolvían, así como el de sus propias personas, con lo que ello suponía para la demanda de recursos hídricos. El caudal del Manzanares, notablemente variable dependiendo de las estaciones del año, no daría abasto para

${ }^{41}$ AHN, Consejos, leg. 35127, 1, pieza separada, fols. 28 y 29. Ése es el caso, por ejemplo, del pleito en materia de aguas mantenido por las poblaciones de Cerceda y Moralzarzal en el siglo Xv. Los jueces, con sede en Manzanares el Real, habían señalado plazos para dictar sentencia, habiéndose incumplido sucesivamente los mismos. En vista de todo ello las partes habían protestado reclamando la susodicha sentencia, que no fue dictada hasta que ambas poblaciones amenazaron con reclamar las costas judiciales además de quejarse formalmente ante el señor del territorio. 
cubrir dichas necesidades juntamente con las de los campesinos que precisaban esos recursos para regar sus campos. Los conflictos se acrecentarían cuando durante los meses de secano, época en la que justamente aumentaba la demanda de agua, el cauce del río a su paso por Madrid quedaba prácticamente seco.

El cúmulo de todas las circunstancias mencionadas convirtió a la región madrileña en una notable excepción por lo que respecta a las necesidades normativas en materia de aguas. Sólo a comienzos del siglo XIX, en los albores de la época constitucional, la profunda transformación del régimen político y jurídico en España traería consigo una legislación uniforme y extensa de los recursos hídricos. A ello hay que añadir profundas reformas en lo que atañe a los sistemas de almacenamiento y distribución de aguas para la capital a través de la creación del Canal de Isabel II.

También la progresiva desaparición de la otrora economía eminentemente agraria de la región y su paulatina industrialización han traído consigo un notable cambio en los aprovechamientos hídricos. Pero ninguna de esas variaciones ha supuesto una solución definitiva frente a la insuficiencia de tales recursos, carencia que sigue siendo objeto de preocupación para las autoridades de las distintas poblaciones que configuran la actual Comunidad Autónoma de Madrid. 